\title{
Effects of additives and secondary phases on the sintering behavior of zinc oxide-based varistors
}

\author{
Chung-Hsin Lu*, Ning Chyi, Hsi-Wu Wong, Wen-Jeng Hwang \\ Department of Chemical Engineering, National Taiwan University, Taipei, Taiwan \\ Received 27 October 1998; received in revised form 2 July 1999; accepted 6 July 1999
}

\begin{abstract}
The influence of additives and secondary phases on the sintering behavior of zinc oxide-based varistors has been investigated in this study. Addition of $\mathrm{Bi}_{2} \mathrm{O}_{3}$ and $\mathrm{Sb}_{2} \mathrm{O}_{3}$ to $\mathrm{ZnO}$ results in rapid shrinkage of the specimens at around $1000^{\circ} \mathrm{C}$. This rapid shrinkage is attributed to the reaction between the pyrochlore phase and $\mathrm{ZnO}$. This reaction has been verified by investigating the system of $\mathrm{ZnO}$ and a synthesized pyrochlore phase $\mathrm{ZnBi}_{1.5} \mathrm{Sb}_{1.5} \mathrm{O}_{7}$. This pyrochlore phase has a cubic symmetry, with a lattice parameter $a_{\mathrm{o}}=10.4438 \AA . \mathrm{ZnBi}_{1.5} \mathrm{Sb}_{1.5} \mathrm{O}_{7}$ is found to react with $\mathrm{ZnO}$ at $1000^{\circ} \mathrm{C}$ to lead to the formation of $\mathrm{Bi}_{2} \mathrm{O}_{3}$, which accelerates the sintering rate of $\mathrm{ZnO}$ through a liquid-phase sintering mechanism. On the other hand, the spinel phase $\alpha-\mathrm{Zn}_{7} \mathrm{Sb}_{2} \mathrm{O}_{12}$ hinders the sintering process as well as the grain growth of $\mathrm{ZnO}$. (C) 2000 Elsevier Science S.A. All rights reserved.
\end{abstract}

Keywords: Zinc oxide; Pyrochlore phase; Sintering; Microstructure

\section{Introduction}

Zinc oxide has been widely used to fabricate varistors since 1970s because of its excellent non-ohmic property [1]. Varistors are important protection devices against voltage surges in solid-state devices and electrical power generation systems [2]. To improve the electrical characteristics of varistors, considerable research efforts have been devoted to study the effects of adding small amounts of various additives to $\mathrm{ZnO}$ [3-7]. The most commonly used additives are $\mathrm{Bi}_{2} \mathrm{O}_{3}, \mathrm{Sb}_{2} \mathrm{O}_{3}, \mathrm{Co}_{3} \mathrm{O}_{4}, \mathrm{MnO}_{2}, \mathrm{Cr}_{2} \mathrm{O}_{3}$, and $\mathrm{NiO}$. Each of these additives plays a different role in enhancing the nonohmic property of $\mathrm{ZnO}$ [8]. However, the presence of these additives results also in the formation of secondary phases in $\mathrm{ZnO}$ [9-11] and different microstructures [12,13]. The types of secondary phases formed depend on the added amount and the type of additive. In general, pyrochlore phase $\mathrm{ZnBi}_{1.5} \mathrm{Sb}_{1.5} \mathrm{O}_{7}$ and spinel phase $\alpha-\mathrm{Zn}_{7} \mathrm{Sb}_{2} \mathrm{O}_{12}$ are found to be the two major compounds coexisting with $\mathrm{ZnO}$ [10].

Although the effects of additives on the electrical properties and microstructure of $\mathrm{ZnO}$ have been explored, how these additives and secondary phases influence the sintering of $\mathrm{ZnO}$, remains unclear. For obtaining highly densified $\mathrm{ZnO}$-based varistors, the basic study of the sintering phenomena is crucial. Hence, the purpose of the present study is

${ }^{*}$ Corresponding author. Tel.: +886-2-3635230; fax: +886-2-3623040 to investigate the sintering behavior of $\mathrm{ZnO}$-based varistors. The additives used in this study are $\mathrm{Bi}_{2} \mathrm{O}_{3}, \mathrm{Sb}_{2} \mathrm{O}_{3}$, and their resultant compounds with $\mathrm{ZnO}$ (pyrochlore phase $\mathrm{ZnBi}_{1.5} \mathrm{Sb}_{1.5} \mathrm{O}_{7}$ and spinel phase $\left.\alpha-\mathrm{Zn}_{7} \mathrm{Sb}_{2} \mathrm{O}_{12}\right)$. Since the preparation of $\mathrm{ZnBi}_{1.5} \mathrm{Sb}_{1.5} \mathrm{O}_{7}$ has not yet been investigated in detail, the formation process of $\mathrm{ZnBi}_{1.5} \mathrm{Sb}_{1.5} \mathrm{O}_{7}$ was studied first. Then, the synthesized pyrochlore phase was added to $\mathrm{ZnO}$. The phase evolution and microstructural development of $\mathrm{ZnO}$, with additives added during sintering, were examined.

\section{Experimental}

Pyrochlore phase $\mathrm{ZnBi}_{1.5} \mathrm{Sb}_{1.5} \mathrm{O}_{7}$ and spinel phase $\alpha$ $\mathrm{Zn}_{7} \mathrm{Sb}_{2} \mathrm{O}_{12}$ were prepared by using reagent grade $\mathrm{ZnO}$, $\mathrm{Bi}_{2} \mathrm{O}_{3}$, and $\mathrm{Sb}_{2} \mathrm{O}_{3}$ as raw materials. These raw materials were weighed according to the desired composition, and ball-milled, using zirconium oxide balls, in ethanol for $48 \mathrm{~h}$. The mixed slurry was dried at about $60^{\circ} \mathrm{C}$ in an evaporator. The dried powders were then pressed and calcined. After $1000^{\circ} \mathrm{C}$ calcination for $4 \mathrm{~h}$, pure $\mathrm{ZnBi}_{1.5} \mathrm{Sb}_{1.5} \mathrm{O}_{7}$ was obtained, while pure $\alpha-\mathrm{Zn}_{7} \mathrm{Sb}_{2} \mathrm{O}_{12}$ was produced after $900^{\circ} \mathrm{C}$ calcination for $4 \mathrm{~h}$. The $\mathrm{ZnO}$ powder was then mixed and ball-milled with the additives of $\mathrm{Bi}_{2} \mathrm{O}_{3}, \mathrm{Sb}_{2} \mathrm{O}_{3}$, $\mathrm{ZnBi}_{1.5} \mathrm{Sb}_{1.5} \mathrm{O}_{7}$, and $\alpha-\mathrm{Zn}_{7} \mathrm{Sb}_{2} \mathrm{O}_{12}$. The mixing ratio for each specimen is listed in Table 1 . In the ZY3 and ZY4 
Table 1

Composition of the mixtures of $\mathrm{ZnO}$ comprising various additives

\begin{tabular}{lllll}
\hline Sample & $\mathrm{ZnO}$ & $\mathrm{Bi}_{2} \mathrm{O}_{3}$ & $\mathrm{Sb}_{2} \mathrm{O}_{3}$ & $\begin{array}{c}\begin{array}{c}\text { Pyrochlore } \\
\mathrm{ZnBi}_{1.5} \mathrm{Sb}_{1.5} \mathrm{O}_{7}\end{array} \\
\mathrm{Zn}_{7} \mathrm{Sb}_{2} \mathrm{O}_{12}\end{array}$ \\
\hline $\mathrm{ZY1}$ & $99.5^{\mathrm{a}}$ & 0.5 & - & - \\
$\mathrm{ZY2}$ & 98.5 & 0.5 & 1.0 & - \\
$\mathrm{ZY3}$ & 99.0 & - & - & - \\
$\mathrm{ZY4}$ & 99.0 & - & - & - \\
\hline
\end{tabular}

${ }^{\mathrm{a}}$ Molar ratio.

systems, $1 \mathrm{~mol} \% \quad \mathrm{ZnBi}_{1.5} \mathrm{Sb}_{1.5} \mathrm{O}_{7}$ and $\alpha-\mathrm{Zn}_{7} \mathrm{Sb}_{2} \mathrm{O}_{12}$ were added to $\mathrm{ZnO}$, respectively. The dried powders were pressed into discs and heated at a rate of $10^{\circ} \mathrm{C} / \mathrm{min}$ up to $1250^{\circ} \mathrm{C}$.

The compounds formed in the quenched specimens were investigated by X-ray powder diffraction analysis (XRD). In order to calculate the relative fractions of different phases in the resultant compounds, intensities of the distinct diffraction peaks, associated with phases (101) for $\mathrm{ZnO}$, (440) for $\mathrm{ZnBi}_{1.5} \mathrm{Sb}_{1.5} \mathrm{O}_{7}$, (511) for $\alpha-\mathrm{Zn}_{7} \mathrm{Sb}_{2} \mathrm{O}_{12}$, (151) for $\beta$ $\mathrm{Zn}_{7} \mathrm{Sb}_{2} \mathrm{O}_{12}$, and (201) for $\beta-\mathrm{Bi}_{2} \mathrm{O}_{3}$, were measured. The relative fraction of each compound was calculated from the ratio of the intensity of the specific diffraction peak of each compound to the sum of the intensity of the specific diffraction peak of all compounds. The sintering behavior of the samples was examined by a dilatometer. The microstructural evolution and particle size of the heated specimens were investigated by scanning electron microscopy (SEM), coupled with energy dispersive X-ray spectroscopy (EDS)

\section{Results and discussion}

\subsection{Preparation of $\mathrm{ZnBi} i_{1.5} \mathrm{Sb}_{1.5} \mathrm{O}_{7}$}

In order to determine the optimum condition for preparing $\mathrm{ZnBi}_{1.5} \mathrm{Sb}_{1.5} \mathrm{O}_{7}$, the starting materials for $\mathrm{ZnBi}_{1.5} \mathrm{Sb}_{1.5} \mathrm{O}_{7}$ were quenched at various temperatures and analyzed by XRD. The XRD patterns of quenched specimens are illustrated in Fig. 1. It is found that, at $500^{\circ} \mathrm{C}$, only the constituent compounds are present. At $600^{\circ} \mathrm{C}$, a small amount of $\mathrm{Bi}_{3} \mathrm{SbO}_{7}$ begins to form. At $800^{\circ} \mathrm{C}, \mathrm{BiSbO}_{4}$ and the pyrochlore phase $\mathrm{ZnBi}_{1.5} \mathrm{Sb}_{1.5} \mathrm{O}_{7}$ begin to appear. The amount of $\mathrm{ZnBi}_{1.5} \mathrm{Sb}_{1.5} \mathrm{O}_{7}$ increases rapidly with a rise in temperature, accompanied by a decrease in the contents of intermediate compounds. After heating at $1000^{\circ} \mathrm{C}$, the formation of $\mathrm{ZnBi}_{1.5} \mathrm{Sb}_{1.5} \mathrm{O}_{7}$ is almost complete.

For enhancing the purity of the obtained $\mathrm{ZnBi}_{1.5} \mathrm{Sb}_{1.5} \mathrm{O}_{7}$, the starting materials were heated at $1000^{\circ} \mathrm{C}$ for $4 \mathrm{~h}$. The XRD pattern of the obtained specimen is shown in Fig. 2. The hkl indexes, $d$-spacings, and relative intensities are listed in Table 2. All lines of the diffraction pattern of $\mathrm{ZnBi}_{1.5} \mathrm{Sb}_{1.5} \mathrm{O}_{7}$ is indexed in terms of a cubic symmetry, with a lattice parameter $a_{\mathrm{o}}=10.4438 \AA$. The observed

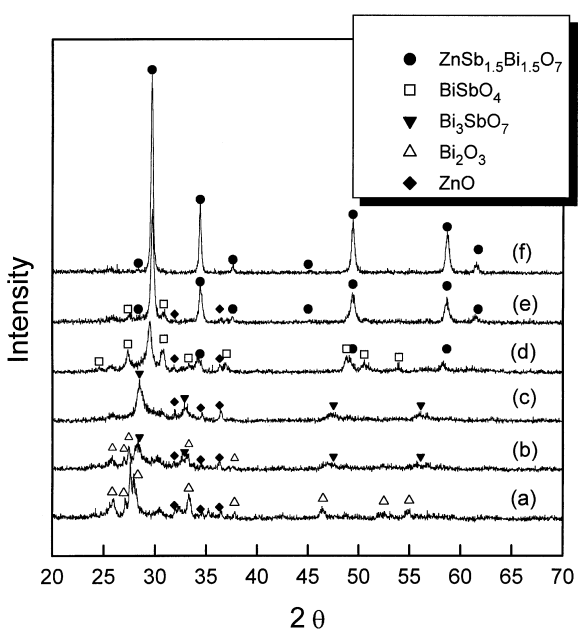

Fig. 1. X-ray diffraction patterns of the starting materials of $\mathrm{ZnBi}_{1.5} \mathrm{Sb}_{1.5} \mathrm{O}_{7}$ quenched at various temperatures: (a) $500^{\circ} \mathrm{C}$, (b) $600^{\circ} \mathrm{C}$, (c) $700^{\circ} \mathrm{C}$, (d) $800^{\circ} \mathrm{C}$, (e) $900^{\circ} \mathrm{C}$, and (f) $1000^{\circ} \mathrm{C}$.

$d$-values $\left(d_{\text {exp }}\right)$ are also compared with the calculated $d$-values $\left(d_{\text {calc }}\right)$, as listed in Table 2 .

\subsection{Influence of the presence of the secondary phases on sintering of $\mathrm{ZnO}$}

The sintering behavior of mixed specimens and pure $\mathrm{ZnO}$ is illustrated in Fig. 3. As shown in the figure, pure $\mathrm{ZnO}$ starts shrinking from about $700^{\circ} \mathrm{C}$, and attains a final

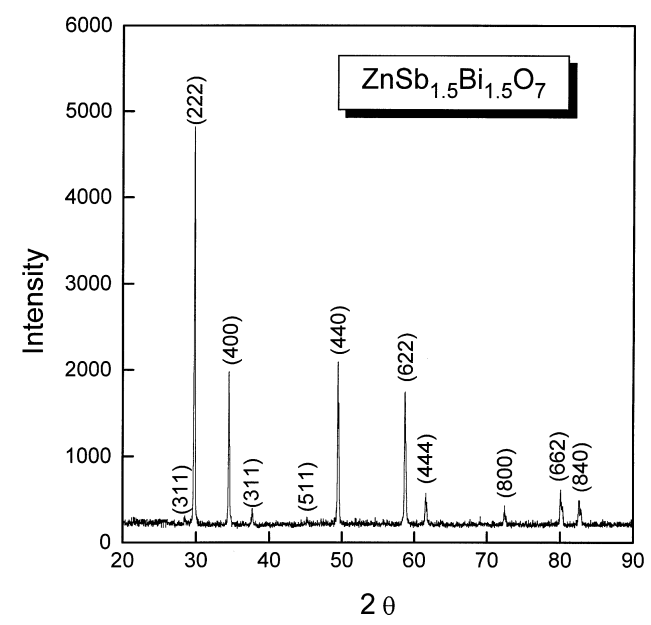

Fig. 2. X-ray diffraction pattern of pure $\mathrm{ZnBi}_{1.5} \mathrm{Sb}_{1.5} \mathrm{O}_{7}$ calcined at $1000^{\circ} \mathrm{C}$ for $4 \mathrm{~h}$ 
Table 2

$\mathrm{X}$-ray diffraction data of $\mathrm{ZnBi}_{1.5} \mathrm{Sb}_{1.5} \mathrm{O}_{7}$

\begin{tabular}{lllr}
\hline $\mathrm{hkl}$ & $d_{\exp }^{\mathrm{a}}$ & $d_{\text {calc }} \mathrm{b}$ & $I / I_{\mathrm{o}}$ \\
\hline 311 & 3.1499 & 3.1489 & 2 \\
222 & 3.0125 & 3.0149 & 100 \\
400 & 2.6093 & 2.6110 & 38 \\
331 & 2.3964 & 2.3960 & 5 \\
511 & 2.0078 & 2.0099 & 2 \\
440 & 1.8448 & 1.8462 & 47 \\
622 & 1.5739 & 1.5745 & 39 \\
444 & 1.5068 & 1.5074 & 9 \\
800 & 1.3057 & 1.3055 & 4 \\
662 & 1.1973 & 1.1980 & 9 \\
840 & 1.1672 & 1.1677 & 8 \\
\hline
\end{tabular}

a Observed $d$-value obtained by experiment.

${ }^{\mathrm{b}}$ Calculated $d$-value based on $a_{\mathrm{o}}=10.4438 \AA$.

shrinkage of $14 \%$ at $1250^{\circ} \mathrm{C}$. In the ZY1 system, which contains $0.5 \mathrm{~mol} \% \mathrm{Bi}_{2} \mathrm{O}_{3}$, the onset temperature for shrinkage is found to be reduced to $650^{\circ} \mathrm{C}$ and the final shrinkage at $1250{ }^{\circ} \mathrm{C}$ reaches $18.5 \%$. The decrease in the onset temperature for shrinkage and the increase in the shrinkage ratio are attributed to the presence of melting $\mathrm{Bi}_{2} \mathrm{O}_{3}$. As for the ZY2 and ZY3 systems, their shrinkage behaviors are very similar, exhibiting nearly overlapping shrinkage curves. In comparison with $\mathrm{ZnO}$, these two systems exhibit a postponed shrinkage behavior. The onset temperature for shrinkage is found to be around $1000^{\circ} \mathrm{C}$. However, at elevated temperatures, both systems exhibit a larger shrinkage ratio than $\mathrm{ZnO}$. On the other hand, in the ZY4 system, which contains $1 \mathrm{~mol} \% \alpha-\mathrm{Zn}_{7} \mathrm{Sb}_{2} \mathrm{O}_{12}$ phase, the onset temperature for shrinkage increases further to $1050^{\circ} \mathrm{C}$.

In order to examine the microstructural evolution in ZY2, $\mathrm{ZY} 3$, and ZY4 systems, the specimens were quenched at $1000^{\circ} \mathrm{C}$ and $1100^{\circ} \mathrm{C}$ during the heating process. At $1000^{\circ} \mathrm{C}$, the microstructures of all four systems were found to be nearly identical, appearing highly porous, with a particle size of around $0.2 \mu \mathrm{m}$. This microstructural observation

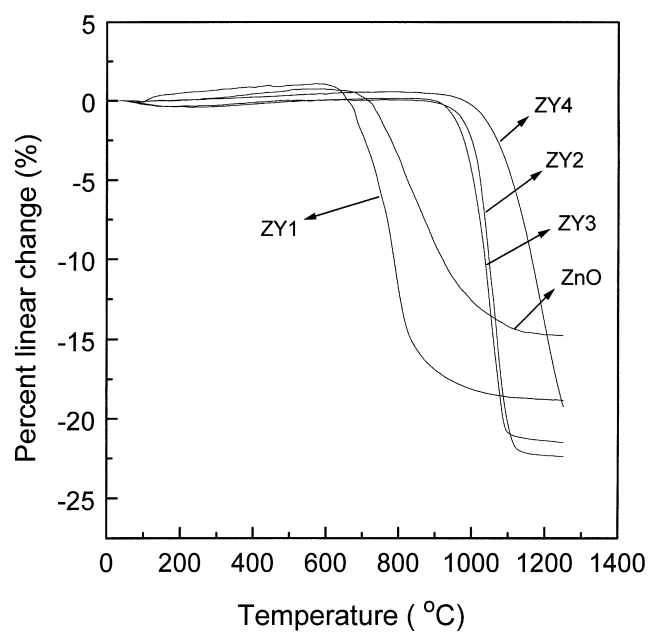

Fig. 3. Shrinkage curves of pure $\mathrm{ZnO}$, and $\mathrm{ZnO}$ mixed with various additives. indicates that these specimens are not densified. A representative SEM photo (ZY2 system) is presented in Fig. 4(a). When the temperature is raised to $1100^{\circ} \mathrm{C}$, the $\mathrm{ZY} 2$ and ZY3 systems rapidly become densified, but not $Z Y 4$. The typical microstructures of ZY2, ZY3, and ZY4, at $1100^{\circ} \mathrm{C}$, are shown in Fig. 4(b,c, and d), respectively. Densified features can be observed clearly for the former two specimens, while ZY4 still exhibits a porous microstructure. In the ZY2 system, $\mathrm{ZnO}$ grains rapidly grow to a size of $6-8 \mu \mathrm{m}$, and some plate-like grains are also formed. The composition of these plate-like grains was identified by EDS and was found to be close to that of $\mathrm{Zn}_{7} \mathrm{Sb}_{2} \mathrm{O}_{12}$. For system $\mathrm{ZY} 3$, a melted microstructure can be observed. These remarkable microstructural variations, found between $1000^{\circ} \mathrm{C}$ and $1100^{\circ} \mathrm{C}$ in the $\mathrm{ZY} 2$ and $\mathrm{ZY} 3$ systems, suggest the occurrence of a liquid-phase sintering process. On the other hand, for the ZY4 system, the microstructure at $1100^{\circ} \mathrm{C}$ remains the same as that at $1000^{\circ} \mathrm{C}$.

\subsection{Reactions occurring in the secondary phases-added $\mathrm{ZnO}$}

In order to investigate the correlation between the formed compounds and sintering behavior, the specimens were quenched at elevated temperatures. The XRD patterns of ZY3 system, quenched at $900^{\circ} \mathrm{C}, 1000^{\circ} \mathrm{C}, 1100^{\circ} \mathrm{C}$, and $1250^{\circ} \mathrm{C}$, are presented in Fig. 5. Notably, the ZY3 system consists of $\mathrm{ZnO}$ and pyrochlore phase $\mathrm{ZnBi}_{1.5} \mathrm{Sb}_{1.5} \mathrm{O}_{7}$. At $90{ }^{\circ} \mathrm{C}$, only $\mathrm{ZnBi}_{1.5} \mathrm{Sb}_{1.5} \mathrm{O}_{7}$ coexists with $\mathrm{ZnO}$; while at $1000^{\circ} \mathrm{C}$, a small amount of $\alpha-\mathrm{Zn}_{7} \mathrm{Sb}_{2} \mathrm{O}_{12}$ is formed. From $1100^{\circ} \mathrm{C}$, the amount of $\mathrm{ZnBi}_{1.5} \mathrm{Sb}_{1.5} \mathrm{O}_{7}$ rapidly decreases and $\beta-\mathrm{Zn}_{7} \mathrm{Sb}_{2} \mathrm{O}_{12}$ is formed. On heating further to $1250^{\circ} \mathrm{C}$, nearly all $\mathrm{ZnBi}_{1.5} \mathrm{Sb}_{1.5} \mathrm{O}_{7}$ is consumed, and $\beta-\mathrm{Zn}_{7} \mathrm{Sb}_{2} \mathrm{O}_{12}$ and $\mathrm{Bi}_{2} \mathrm{O}_{3}$ are formed. The results in Figs. 3 and 5 reveal that the rapid shrinkage and remarkable microstructural variations in ZY3 is caused by the reaction between the pyrochlore phase and $\mathrm{ZnO}$.

Variations in the relative amounts of secondary compounds formed in systems ZY2, ZY3, and ZY4 are shown in Fig. 6. It is found that, at $1000^{\circ} \mathrm{C} \mathrm{ZnBi}_{1.5} \mathrm{Sb}_{1.5} \mathrm{O}_{7}$ is present in ZY2 system. However, after $1100^{\circ} \mathrm{C}$ heating, $\beta$ $\mathrm{Zn}_{7} \mathrm{Sb}_{2} \mathrm{O}_{12}$ is formed, along with a decrease in $\mathrm{ZnBi}_{1.5} \mathrm{Sb}_{1.5} \mathrm{O}_{7}$. Therefore, in $\mathrm{ZY} 2$ and $\mathrm{ZY} 3$ systems, the following reaction, proposed by Inada [11], is believed to occur:

$17 \mathrm{ZnO}+4 \mathrm{ZnBi}_{1.5} \mathrm{Sb}_{1.5} \mathrm{O}_{7} \rightarrow 3 \beta-\mathrm{Zn}_{7} \mathrm{Sb}_{2} \mathrm{O}_{12}+3 \mathrm{Bi}_{2} \mathrm{O}_{3}$

The presence of pyrochlore phase in ZY2 and ZY3 plays a similar role in the sintering of $\mathrm{ZnO}$, regardless of whether pyrochlore phase is added to $\mathrm{ZnO}$ (in ZY3) or produced by the reactions between the additives and $\mathrm{ZnO}$ (in $\mathrm{ZY} 2$ ). When pyrochlore phase reacts with $\mathrm{ZnO}$ at $1000^{\circ} \mathrm{C}, \beta$ $\mathrm{Zn}_{7} \mathrm{Sb}_{2} \mathrm{O}_{12}$ and $\mathrm{Bi}_{2} \mathrm{O}_{3}$ are formed. The latter compound accelerates the sintering rate of $\mathrm{ZnO}$ through a liquid-phase sintering mechanism. The melting point of pyrochlore phase 


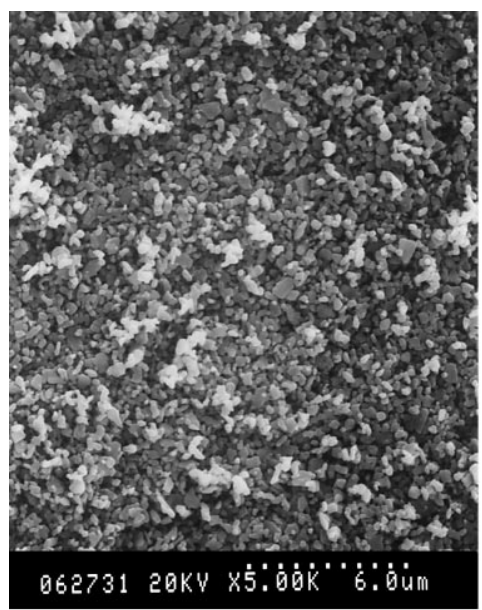

(a)

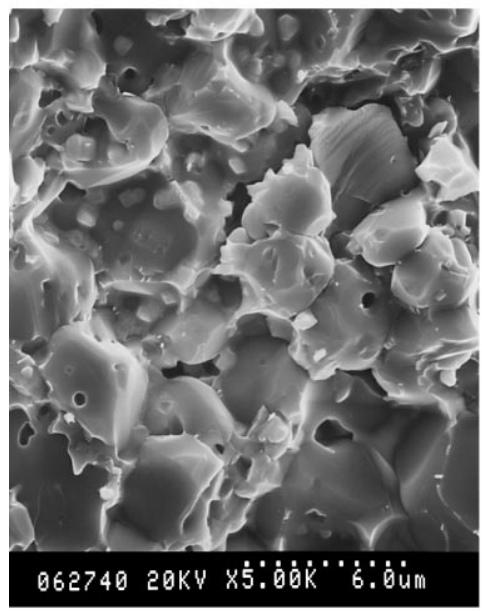

(c)

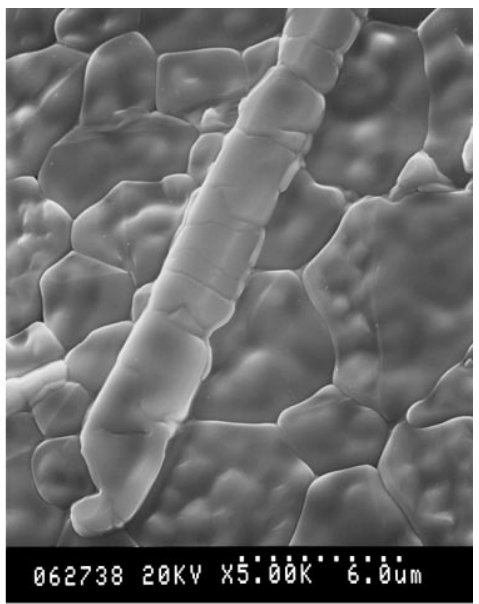

(b)

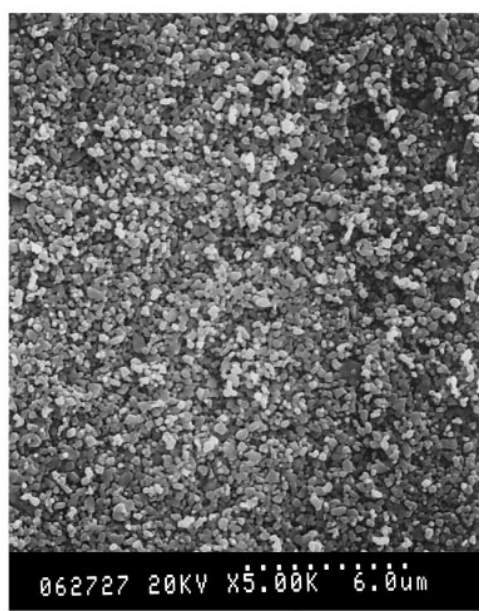

(d)

Fig. 4. Scanning electron micrographs of (a) ZY2 quenched at $1000^{\circ} \mathrm{C}$, and (b) ZY2, (c) ZY3 and (d) $\mathrm{ZY} 4$ quenched at $1100^{\circ} \mathrm{C}$.

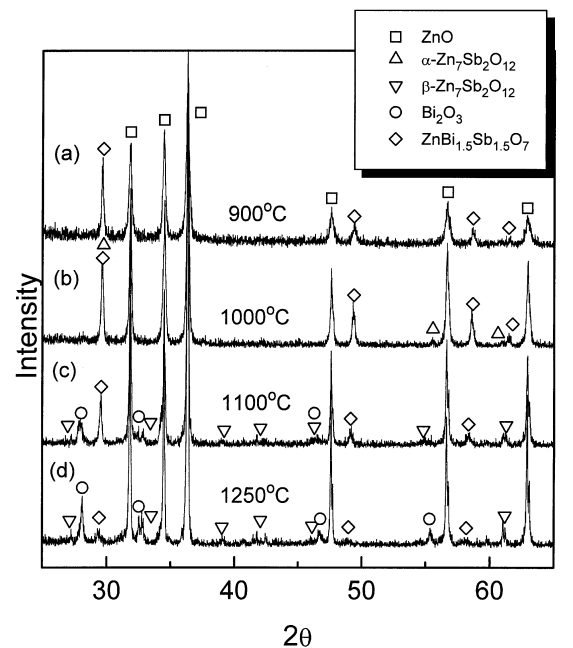

Fig. 5. X-ray diffraction patterns of $\mathrm{ZY} 3$ quenched at (a) $900^{\circ} \mathrm{C}$, (b) $1000^{\circ} \mathrm{C}$, (c) $1100^{\circ} \mathrm{C}$, and (d) $1250^{\circ} \mathrm{C}$.

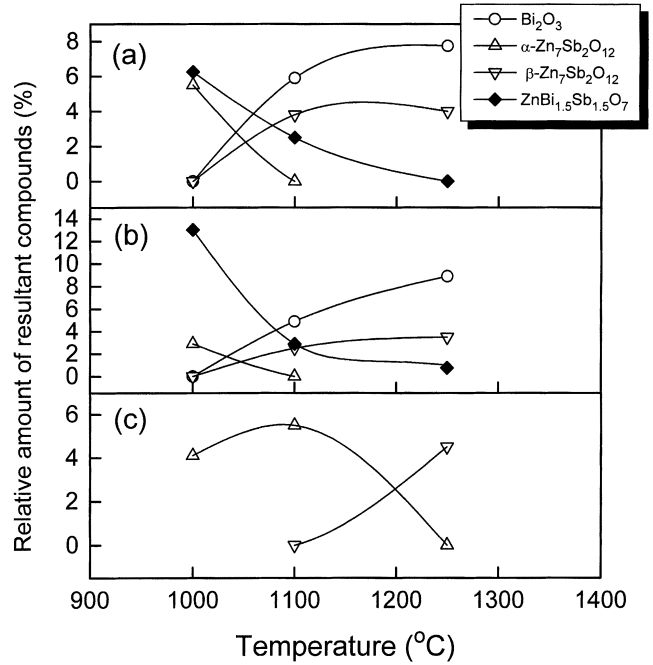

Fig. 6. Variations in the relative amounts of secondary compounds formed in (a) ZY2, (b) ZY3, and (c) ZY4 as a function of temperature. 
has been reported to be $1280^{\circ} \mathrm{C}$ [11]. Therefore, the rapid shrinkage of ZY2 and ZY3 systems at around $1000^{\circ} \mathrm{C}$ (Fig. 3 ) is caused by the reaction between $\mathrm{ZnO}$ and pyrochlore phase, rather than the direct melting of the pyrochlore phase. The remarkable microstructural variations (Fig. 4) in the ZY2 and ZY3 systems are confirmed to result from the formation of liquid phase through the reaction of pyrochlore phase.

In the ZY4 system, no pyrochlore phase is formed at elevated temperatures, and, consequently, no rapid shrinkage is observed around $1000^{\circ} \mathrm{C}$. Only $\alpha$ and $\beta-\mathrm{Zn}_{7} \mathrm{Sb}_{2} \mathrm{O}_{12}$ compounds are found to coexist in the ZY4 system. $\beta$ $\mathrm{Zn}_{7} \mathrm{Sb}_{2} \mathrm{O}_{12}$ is formed from the phase transformation of $\alpha$ $\mathrm{Zn}_{7} \mathrm{Sb}_{2} \mathrm{O}_{12}$, rather than from the reaction between $\mathrm{ZnO}$ and pyrochlore phase. Apparently, the spinel phase $\alpha$ $\mathrm{Zn}_{7} \mathrm{Sb}_{2} \mathrm{O}_{12}$ does not react with $\mathrm{ZnO}$ to form secondary phases. Furthermore, based on the results in Figs. 3 and 4 , the presence of spinel phase appears to postpone the sintering process, and hinders the growth of $\mathrm{ZnO}$ grains.

\section{Conclusions}

The shrinkage behavior of $\mathrm{ZnO}$-based varistors has been investigated in this study. With the addition of $\mathrm{Bi}_{2} \mathrm{O}_{3}$ and $\mathrm{Sb}_{2} \mathrm{O}_{3}$, the specimen rapidly shrinks from $1000^{\circ} \mathrm{C}$. The rapid shrinkage is related to the reaction between the pyrochlore phase and $\mathrm{ZnO}$. This reaction has been con- firmed by investigating the system of $\mathrm{ZnO}$ and a synthesized pyrochlore phase $\left(\mathrm{ZnBi}_{1.5} \mathrm{Sb}_{1.5} \mathrm{O}_{7}\right.$ with $a_{\mathrm{o}}=10.4438 \AA$ ). This pyrochlore phase is found to react with $\mathrm{ZnO}$ at $1000^{\circ} \mathrm{C}$ to result in the formation of $\mathrm{Bi}_{2} \mathrm{O}_{3}$, which accelerates the sintering rate of $\mathrm{ZnO}$ through a liquid-phase sintering mechanism. On the other hand, addition of spinel phase $\alpha-\mathrm{Zn}_{7} \mathrm{Sb}_{2} \mathrm{O}_{12}$ not only postpones the sintering process of $\mathrm{ZnO}$, but also hinders the growth of $\mathrm{ZnO}$ grains.

\section{References}

[1] M. Matsuoka, Jpn. J. Appl. Phys. 10 (1971) 736.

[2] L.M. Levinson, H.R. Philip, IEEE Trans. Parts. Hybrid Packaging PAP-13 (1977) 338

[3] K. Eda, J. Appl. Phys. 51 (1980) 4453.

[4] A. Kusy, T.G.M. Kleinpenning, J. Appl. Phys. 54 (1983) 2900.

[5] A. Miralles, A. Cornet, A. Herma, J.R. Morante, Mater. Sci. Eng. A 109 (1989) 201.

[6] Y.C. Chen, C.Y. Shen, H.Z. Chen, Y. Fang, L. Wu, Jpn. J. Appl. Phys. 30 (1991) 84

[7] S.A. Pianaro, E.C. Pereira, L.O.S. Bulhoes, E. Longo, J.A. Varela, J. Mater. Sci. 30 (1995) 133.

[8] K. Eda, IEEE Electr. Insulation 5 (1989) 28

[9] J. Wong, J. Appl. Phys. 46 (1975) 1653.

[10] M. Inada, Jpn. J. Appl. Phys. 17 (1978) 1.

[11] M. Inada, Jpn. J. Appl. Phys. 19 (1980) 409.

[12] J.C. Kim, E. Goo, J. Mater. Sci. 24 (1989) 76.

[13] T. Asokan, R. Freer, J. Mater. Sci. 25 (1990) 2447. 